\title{
Lectura de Domingo de Soto del De legibus ciceroniano: El binomio ley eterna-racionalidad en De Iustitia et Iure
}

Domingo de Soto's interpretation of the ciceronian De legibus: The binomial eternal law-rationality in De Iustitia et iure

Laura Corso de Estrada Conicet/UCA-UBA Argentina lauracorso@uca.edu.ar

DOI: https://doi.org/10.15366/bp2021.26.003 Bajo Palabra. II Época. No26. Pgs: 59-74 
Recibido: 12-09-2020

Aceptado: 7-10-2020

\section{Resumen}

Los escritos ciceronianos son fuente de transmisión crítica del legado estoico $y$, asimismo, de una reelaboración que conlleva componentes de enseñanza platónico-académica que autores escolásticos recogieron con motivo del tratamiento de la quaestio de la ley. En este artículo, me propongo llevar a cabo una exégesis del De Iustitia et Iure I de Domingo de Soto con el objeto de examinar las aportaciones del De legibus de Cicerón en exposiciones del maestro de Salamanca sobre el binomio: ley eterna-racionalidad.

Palabras clave: ley, naturaleza, racionalidad, Cicerón, escolástica.

\section{Abstract}

The writings of Cicero are sources of critical transmission of stoic legacy, and in the same way of a reelaboration containing elements of platonic-academic teaching that scholastic authors collected in relation with the treatment of the quaestio about law. My purpose in this paper is to fulfill an exegesis of the De Iustitia et iure I of Domingo de Soto to examinate the contribution of Cicero's De legibus in expositions of the Salamanca's master about the binomial eternal law-rationality.

Keywords: law, nature, rationality, $C i-$ cero, Scholasticism. 


\section{Consideraciones antecedentes}

En el Proemio de De Iustitia et Iure, Domingo de Soto comienza por considerar con cuidada formulación la pertenencia epistemológica que conviene a la consideración del "ius" y de la "iustitia", núcleos del desarrollo de su obra. De modo manifiesto estas temáticas corresponden a la labor del jurisconsulto, pero Soto subraya que ha de advertirse que "el [derecho] Civil [se ha desarrollado] por mediación de las costumbres" ${ }^{1}$ y que, por ello, cabe a los "filósofos" ("philosophi"): "examinar el [derecho] Civil desde los principios de la filosofía" 2 . Soto asienta esta postura en la sentencia ciceroniana de De legibus donde se afirma que "la ciencia del derecho" ("iuris diciplina"): "No ha de ser tomada ni del edicto del pretor, ni de las Doce Tablas, sino que ha de ser enteramente considerada desde la profundidad de la filosofía" ${ }^{3}$. Sentencia con la que Soto apela al pasaje de De legibus I, 5, 17, donde Tito Pomponio Ático, amigo de Marco Tulio Cicerón y uno de los interlocutores del diálogo, formula en rigor como pregunta lo que el texto de Soto enuncia como aseveración, al describir el modo en que Cicerón ha de desarrollar su exposición sobre el "ius" y la "lex".

No podría decirse que la pregunta de Ático que Soto incorpora en su escrito como una afirmación del texto ciceroniano sea una exégesis incorrecta del maestro salmantino. Pues la pregunta de Ático es fruto de desarrollos precedentes donde -de modo definido- Cicerón ha sostenido, tras haber sido convocado por sus interlocutores a disertar sobre la naturaleza del derecho, la postura contenida en la pregunta que nos ocupa en el texto ciceroniano. De allí que Ático la formule con una modalidad algo conclusiva; añadiendo, más allá de lo que Soto refiere, que: por una parte, tomar el derecho del edicto del pretor es lo regular en la Roma de su tiempo y que, por otro lado, las Doce Tablas han regido a los antepasados 4 .

La respuesta de Cicerón a Ático en el locus de De legibus es enfática: "En efecto ... en esta conversación no indagamos cuál es el modo de hacer provisiones lega-

\footnotetext{
1 Domingo de Soto, De Iustitia et Iure, Proemium: "Civilia vero ex media morum".

Sigo en este estudio mi propia versión directa del texto latino de: De Iustitia et Iure. Libri Decem (ed. facsimilar), con Introducción histórica y teológico-jurídica de P. Venancio Carro, Madrid, Instituto de Estudios Políticos, 1967 , vol. I.

2 Ibid., Proemium: "Civilia ex principiis philosophiae axaminare".

${ }^{3}$ Ibid., Proemium: "Unde Cicero De legibus I, non a pretoris edicto, neque a 12 tabulis, sed penitus ex intima philosophia hauriendam iuris censet".

${ }^{4}$ Cf. Cicerón, De legibus I, 5, 17.
} 
les, o cuál es la respuesta que hemos de dar a cada consulta jurídica. Por más que esto sea importante, como realmente lo es, y haya sido sostenido en el pasado por muchos hombres ilustres [...] en nuestro caso debemos alcanzar en esta disertación la razón de ser universal del derecho en su conjunto y de las leyes [...] En efecto, debemos explicar la naturaleza del derecho" ${ }^{5}$. Con esta respuesta ante la pregunta de su interlocutor, Cicerón ha definido un plano epistemológico en el tratamiento de la problemática acerca del "ius", y lo ha situado en un ámbito que, en tanto tiene por objeto su "razón de ser" ("causa"), corresponde al plano de universalidad propio de la filosofía. Conforme a lo cual Cicerón se ha propuesto, con tal aspiración de universalidad, trascender con su elaboración sobre el "ius" los límites de Roma, y de cualquier otra restricción político-territorial. Por lo que como acertadamente observa J. Turpin, el De legibus ciceroniano constituye, en el contexto del pensamiento latino antiguo, un esfuerzo especulativo por asignar a la filosofía un papel mediador respecto del tratamiento de la ley civil ${ }^{6}$.

Éste es el contexto inmediato de la postura ciceroniana que Soto hace presente en los primeros apartados de su Proemio, por lo que su relectura evocativa del texto parece conducirnos a advertir que adhiere a su contenido teórico y, consecuentemente, a su definición en el plano epistemológico de su consideración sobre la naturaleza del "ius". Por otra parte, tal vez pueda presumirse que también haya tenido en mente pasajes ciceronianos del De inventione Rhetorica, recurrentemente citados desde tiempos medievales, acerca del papel de la "costumbre" ("mos") en la constitución de las leyes, a lo cual Soto hace referencia como ya mencioné supra con motivo de su Proemio. Tal el caso del pasaje donde Cicerón sostiene que "las cosas que proceden de la naturaleza y son reconocidas por la costumbre, son sancionadas por el temor de las leyes" 7 .

Mis consideraciones iniciales de estos pasajes del Proemio coinciden, al menos en parte, con el desarrollo que M. Scattola dedica a la fundamentación filosófica de la justicia que Soto desarrolla en De Iustitia et Iure. En efecto, Scattola identifica

\footnotetext{
${ }^{5}$ Ibid., I, 5, 17: "Non enim id quaerimus hoc sermone [...] quem ad modum caveamus in iure, aut quid de quaque consultatione respondeamus. Sit ista res magna, sicut est, quae quondam a multis claris viris [...] sed nobis ita complectenda in hac disputatione tota causa est universi iuris ac legum [...] Natura enim iuris explicanda nobis est" (el subrayado no pertenece al texto).

A lo largo de este estudio sigo mi propia traducción directa del texto latino del De legibus ciceroniano, tomado fundamentalmente de la edición crítica de De Plinval, G., Cicéron, Traité Des Lois, Paris, Les Belles Lettres, 1968. Traducción de mi autoría que he vertido en: Corso de Estrada, L., Marco Tulio Cicerón, Sobre las Leyes. Edición Bilingüe, Traducción anotada, Introducción y Apéndices, Buenos Aires, COLIHUE-CLÁSICA, 2019.

${ }^{6}$ Cfr. Turpin, J., "Cicéron, De legibus I-II et la religion romaine: une interpretation philosophique à la veille du principat”, Aufstieg und Niedergang der Römischen Welt, 1986, II 3, p. 1908.

${ }^{7}$ Cicerón, De inventione Rhetorica II, 53, 160: "res et ab natura profectas et ab consuetudines probatas, legum metus [...] sanxit".
} 
el De legibus de Cicerón como fuente de la "reivindicación de la filosofía como fundamento del derecho" y, tras detenerse en algunos de los pasajes que también he abordado aquí, subraya el papel que en el Proemio ya Soto asigna específicamente a la filosofía en la consideración de la naturaleza de lo jurídico con una determinación neta que difiere de la de otros autores salmantinos ${ }^{8}$. Como he justificado en estudios precedentes, los escritos ciceronianos han constituido una fuente de transmisión crítica del acervo estoico y, además, una reelaboración que conlleva la sinergia de componentes principalmente platónicos pero también aristotélicos, que maestros de la Escolástica medieval y salmantina tuvieron la aptitud de acoger en relación con sus propios tratamientos acerca de la quaestio de la ley.

Según he examinado en otros estudios, desarrollos significativos de Tomás de Aquino ${ }^{9}$, y de Domingo de Soto ${ }^{10}$, son expresión de tal vía de recepción de fuentes. Y es mi propósito en este artículo volver sobre esta temática para considerar, siguiendo desarrollos del De Iustitia et Iure I de Domingo de Soto en torno al binomio ley-racionalidad, algunas aportaciones de la tradición filosófica ciceroniana presentes en la elaboración del maestro de Salamanca. Tradición romana que, según hemos advertido, Soto hace presente en el inicio de su Proemio.

\section{Relectura de las definiciones ciceronianas de "lex" en De legibus I y II. Clasificación de lex aeterna y de lex naturalis}

Domingo de Soto eXamina en la Quaestio I: De lege in COMmuni, pues -según indica sobre el fin del Proemio- si se sigue a Cicerón en De officiis ${ }^{11}$, el orden de una indagación debe comenzar por "la naturaleza de la cosa" ("substantia rei") que se expresa en la definición de la misma. De allí, la fuente en la que centra su especulación sobre el tema, el texto de Tomás de Aquino de Summa Theologiae I-II q. 90: "De essentia legis" y, consecuentemente, el propósito del a.1 de dicha quaestio: "Si

\footnotetext{
${ }^{8}$ Cfr. Scattola, M., "La virtud de la justicia en la doctrina de Domingo de Soto", Anuario Filosófico 45/2, 2012, pp. $315,317,318$.

9 Entre otros estudios: Corso de Estrada, L., Naturaleza y vida moral. Marco Tulio Cicerón y Tomás de Aquino, Pamplona, EUNSA, 2008; "Natura ut ratio. Componentes del finalismo de tradición estoica en Rabano Mauro, Felipe Canciller y Tomás de Aquino", De natura, La naturaleza en la Edad Media, J. Fuertes Herreros-A. Poncela González (edd.), Ediciones Húmus, Gabinete de Filosofía Medieval- Publicaciones Salamanca, 2015, vol. I, pp. 63-79.

${ }^{10}$ Entre otros estudios: Corso de Estrada, L., "Tesis helenísticas en exégesis escolásticas: 'Conformidad con la naturaleza': Alberto Magno, Tomás de Aquino y Domingo de Soto", en Right and Nature in the First and Second Scholasticism, Rencontres de Philosophie Médiévale, A. Culleton-R. Hofmeister Pich (edd). Brepols, Turnhout, 2014, pp. 271-284.

${ }^{11}$ Cfr. Cicerón, De officiis I, 1, 7.
} 
hay alguna entre las definiciones de ley que proceden de los maestros que se establece como apropiada". Soto pondera que la definición ("definitio legis") a la que Tomás de Aquino arriba en S. Th. I-II q. 90, a.4, c., es la que enuncia debidamente la naturaleza de la ley universalmente considerada, cuando formula que: "no es otra cosa que cierta ordenación de la razón con respecto al bien común, promulgada por aquél que tiene a su cuidado la comunidad" ${ }^{12}$. Pues, en efecto, en ella se encuentran contenidos: "genus legis", "finis", "causa" y la "forma" de establecerla, a cuyo análisis dedica cuatro artículos sucesivos. Y si bien no pueden ser objeto de nuestro presente análisis el seguimiento del estado de la cuestión al que nuestro autor somete cada uno de estos componentes de la naturaleza de la ley, ni las aportaciones con las que complementa la definición tomista que lo ocupa, nos detendremos en las tesis centrales que enuncia Soto con motivo de su recepción de dicha definición tomista. Esto es:1) la ley es "ordenación" ("ordinatio") de la razón ${ }^{13}$; 2) "toda ley, para que sea sólida y estable, debe mover a los súbditos al bien común" ${ }^{14}$; 3) la ley no puede ser obra de cualquier hombre sino de la "república" ("republica") o de quien la tiene a su cuidado ("curam habens") ${ }^{15}$; 4) pertenece a la esencia de la ley su promulgación, dado que "ninguna ley tiene algún vigor como ley, antes de la promulgación" ${ }^{16}$.

${ }_{12}$ Cfr. Tomás de Aquino, Summa Theologiae I-II q. 90, a.4, c.: "El sic [...] potest colligi definitio legis, quae nihil est aliud quam quaedam rationis ordinatio ad bonum commune, ab eo qui curam communitatis habet, promulgata”.

${ }^{13}$ Cfr. Domingo de Soto, op.cit., I, q. 1, a. 1. Cabe ahora simplemente hacer mención al hecho de que Soto aporta a la determinación del género de la ley que ha formulado Tomás de Aquino en S. Th. I-II q. 90, a.4, c., otra nota esencial, al sostener que no sólo es: “ordinatio", sino también "praeceptio", esto es: "prescripción”, en tanto que la ley no sólo ordena o dirige la vida práctica, sino que en tal ordenación: prescribe como ley. Cuestión que conduciría a una compulsa específica entre lo que aquí aduce Soto y el alcance de lo que Tomás de Aquino precisa en S. Th. I-II, q. 90, a.1, ad 3, en relación con el papel de la voluntad en el acto de ordenación que procede de la razón práctica.

En el contexto de este debate, Soto también trae a cuento la vinculación etimológica que Cicerón establece entre "lex" y el verbo "legere" ("elegir"); cfr. Cicerón, De legibus I, 6, 19. Pero con motivo de su exégesis del pasaje Soto subraya, sin descartar esta apreciación ciceroniana, la neta postura del autor romano en coincidencia con la suya propia, cuando define también en Ibid.: "quod lex est mens ratioque prudentis, iurisque atque iniuria regula", esto es: "que la ley es entendimiento y razón del prudente, regla de lo justo y de lo injusto"; como, en efecto, se determina en el mismo sentido en el texto del De legibus ciceroniano I, 6, 19, que cita Soto en op. cit., I, q. 1, a.1.

${ }^{14}$ Ibid., I, q. 1, a. 2: "Lex omnis, quod solida fit et firma, in commune bonum debet subditos promovere". En relación con su análisis acerca de la causa final de la ley, Soto introduce una doble consideración en torno al bien común: a) el bien común entendido como "felicitas naturalis", la que identifica en la "república" ("republica") temporal con un estado "apacible" ("quietus"), "de tranquilidad” ("tranquillus") y "de paz" ("pacificus"); b) "felicitas supernaturalis"), la que ciertamente identifica con el fin último trascendente, al que se ha de ordenar el bien temporal.

15 Ibid., I, q. 1, a. 3; en este sentido Soto subraya la proporción que ha de haber entre la causa eficiente y la final.

${ }^{16}$ Ibid., I, q. 1, a. 4: "Nulla lex ullum habet vigorem legis, ante promulgationem", en relación con lo cual se precisa enfáticamente que ello "es probado por la naturaleza de la ley misma. En efecto, es regla y medida de nuestras 
Pero por una parte, en la misma quaestio I, con motivo de su análisis de otras definiciones de ley, Soto recoge y clasifica las dos definiciones de ley que Cicerón enuncia en su De legibus. Así, el maestro salmantino cita a continuación de la definición tomista de Summa Theologiae, en primer lugar, la segunda de las definiciones ciceronianas de dicha obra, la de De legibus II, evocando que en ella se dice que: "La ley es algo eterno, que rige el mundo en su totalidad, sabiduría para imperar y para prohibir" ${ }^{17}$. Y como procuraré poner de manifiesto, la prioridad que concede a esta definición sobre la segunda de las definiciones de De legibus, la que en rigor figura en un libro anterior de la obra, responde a la prioridad metafísica de tal ley y, consecuentemente, a su significación matriz en la jerarquía de las leyes. Pues Soto lleva a cabo una exégesis de la misma conforme a la cual clasifica dicha ley bajo la especie de "lex aeterna", al indicar expresamente que por su contenido tal definición: "pertenece de modo propio a la Ley Sempiterna de Dios" ${ }^{18}$.

Cicerón ha expuesto en su corpus más propiamente filosófico al menos seis formulaciones centrales sobre el "naturae ius" y la "lex naturalis" ${ }^{19}$ y, en ese contexto, es posible conceder a Soto que, algunas de esas definiciones, ofrecen sustento a su exégesis. Dado que para Cicerón, más allá de la clasificación que el maestro salmantino lleva a cabo en De Iustitia et Iure, la primera predicación de la noción de "lex naturalis" cabe a una ley supra-mundana que se identifica con la racionalidad divina que rige el universo en su conjunto y que el mismo Cicerón calificó en De legibus II, precisamente por ello, como una "lex caelestis" ${ }^{20}$. En De legibus II, Cicerón sostiene que "la ley no es ni una creación del genio de los hombres, ni alguna resolución de los pueblos, sino algo eterno que rige el mundo entero por la sabiduría de lo que ordena y de lo que prohıbe" ${ }^{21}$; formulaciones que -como hemos apreciado inmediatamente supra-Soto hace presente en su evocación de la

acciones, y una regla es vana a no ser que se aplique a los que obran; pero no es posible que sea aplicada si no se tiene conocimiento de ésta.

Bajo este respecto, Soto aborda asimismo la problemática acerca de la promulgación de la ley natural, en la que también se cumpliría esta condición por obra de hallarse "inscripta" ("scripta") en la "mens" humana; cuya manifestación no se hallaba oscurecida en el estado de inocencia. Sobre la concepción de Soto acerca de la índole de la ley natural, volveré un poco más adelante en ap. III de este estudio.

${ }^{17}$ Ibid., I, q. 1, a.1: "Nam illa Ciceronis libro 2 De Leg. Lex est aeternum quoddam, quod universum mundum regit, imperandi prohibendique sapientia".

18 Ibid., I, q. 1, a.1: "sempiternae Dei legi peculiaris est".

${ }_{19}$ Me he extendido analíticamente sobre este tema en: Corso de Estrada, L., "Fases de la filosofía ciceroniana del ius y de la lex”, Marco Tulio Cicerón, Sobre las Leyes. Edición Bilingüe, Traducción anotada, Introducción y Apéndices, op. cit., pp. XCVIII-CV.

${ }^{20}$ Cfr. Cicerón, De legibus II, 4, 9.

${ }^{21}$ Ibid., II, 4, 8: "Hanc igitur video sapientissimorum fuisse sententiam, legem neque hominum ingeniis excogitatam, nec scitum aliquod esse populorum, sed aeternum quiddam, quod universum mundum regeret imperandi prohibendique sapientia”. 
definición de "lex" que clasifica como "aeterna". Bajo este respecto el texto ciceroniano ofrece sustento a su exégesis, dado que Cicerón mismo precisa que ésta es "prima lex" y asimismo "vera lex", a la que describe: "aquella Primera y Suprema Ley es el Entendimiento del Dios, que conforme a la razón establece ya las obligaciones, ya las prohibiciones para todas las cosas" 22 , "es coeterna con el Dios que gobierna y que protege el cielo y la tierra" ${ }^{23}$. Esto es: "La Verdadera Ley y la que es Primera, la que tiene la aptitud para ordenar y para prohibir, es la Recta Razón del Sumo Júpiter" 24, "el Entendimiento divino es la Ley Suma" ${ }^{25}$. Éstas son las palabras de Cicerón en el locus de De legibus II que Soto evoca, y que claramente desplaza y resignifica, más allá de la complejidad que supone una analítica de la concepción ciceroniana acerca de lo divino ${ }^{26}$, en un contexto histórico-teórico diverso, creacionista y expresivo de una concepción definidamente trascendente de la naturaleza divina.

La posición ciceroniana sobre la predicación primera del término "lex" en el sentido indicado tiene firme sustento en otros desarrollos de sus escritos. Así, en pasajes cronológicamente precedentes a De legibus, como en De republica III, 33, 22, locus clásico de la posición de Cicerón sobre la lex naturae, se afirma que: "la Verdadera Ley es [...] Ley eterna e inmutable [...] habrá un solo Dios como Maestro y Soberano de todas las cosas; Autor, Juez y Promulgador de la ley" ${ }^{27}$; y de un modo semejante, en el maduro De offciiis, donde retoma la formulación de ley como "lex divina" ${ }^{28}$. Por lo que bajo este contexto en los desarrollos de De legibus II que evoca Soto, como en otras obras suyas, Cicerón se ha definido a favor de una predicación primera de la noción de "lex" que conlleva una concepción cósmico-teológica de la realidad por la que sostiene la existencia de una Razón divina que se revela en el finalismo natural del universo en su conjunto. Soto pondera en su propio marco

\footnotetext{
${ }^{22}$ Cfr. Ibid., II, 4, 8: "Ita principem legem illa et ultimam mentem esse dicebant omnia ratione aut vetantis dei".

${ }^{23}$ Cfr. Ibid., II, 4, 9: “aequalitas illius caelum atque terras tuentis et regentis dei”.

24 Cfr. Ibid., II, 4, 10: "lex vera atque princeps, apta ad iubendum et ad vetandum, ratio est recta summi Iovis".

25 Cfr. Ibid., II, 5, 11: “illa divina mens summa lex est”.

${ }^{26}$ Me he detenido en consideraciones relativas a la sinergia de componentes platónicos y estoicos de su concepción sobre la ley como naturaleza divina en: Corso de Estrada, L., Naturaleza y vida moral. Marco Tulio Cicerón y Tomás de Aquino, op. cit., I, cc 2 y 3 ; y en: Corso de Estrada, L., "Lectura filosófica de la naturaleza", Marco Tulio Cicerón, Sobre las Leyes. Edición Bilingüe, Traducción anotada, Introducción y Apéndices, op. cit., pp. LXI-LXVII. Cfr. entre estudios especializados sobre el tema: Lévy, C., Cicero Academicus. Recherches sur les Académiques et sur la Philosophie Cicéronienne, Paris-Rome, Palais Farnèse-École Française de Rome, 1992, pp. 623-635, passim; Barnes, J. "Antiochus", Philosophia Togata I, Griffin, M., Barnes, J. (edd.), Oxford, Clarendon Press, 1997, pp. 79 y ss.

${ }_{27}$ Cfr. Cicerón, De republica III, 33, 22: "Est quidem vera lex [...] lex et sempiterna et immutabilis [...] unusque erit communis quasi magister et imperator omnium deus, ille legis huius inventor, disceptator, lator."

${ }^{28}$ Cfr. Cicerón, De officiis III, 5, 23.
} 
especulativo esta predicación de ley, y la inserta en una categoría específica, si bien me detendré un poco más adelante en algunas notas de su reelaboración ${ }^{29}$.

Por otra parte, en la misma quaestio I y con motivo del citado análisis de diversas definiciones de ley, Soto recoge y clasifica otra de las definiciones ciceronianas de De legibus, la cual hace presente -siguiendo de modo textual- la que Cicerón enuncia en I, 6, 18. Así dice Soto: "aquélla, la que enunciara antes en el libro I: 'la ley es razón suma, ínsita en la naturaleza, que ordena lo que ha de hacerse y que prohíbe lo contrario" " 30 . Definición ciceroniana que Soto clasifica como la "que no se extiende más allá [del ámbito] de las leyes naturales" ${ }^{31}$ y la que, por ende, se identifica con una "ley natural" ("lex naturalis"). En rigor, y como puede apreciarse en el enunciado de la definición misma, Cicerón no desiste en ella de la predicación primera y propia de ley que ya hemos considerado pues, en efecto, en ella dice que "lex est ratio summa" y, por ende, su correlato es supra-mundano.

Pero como también se enuncia en la definición que ahora Soto hace presente, tal ley se halla "insita in natura" y, consecuentemente, la naturaleza del mundo por ella penetrada se encuentra regida por su racionalidad que prescribe como ley. De allí que Cicerón haya propuesto una identificación de la "natura" con la "ratio" y con la "lex", por lo que la naturaleza del mundo en su conjunto porta un contenido intrínseco, una racionalidad fundante del orden perfectivo de los seres que lo habitan y, por consiguiente, de su orden natural-universal. En definitiva, Cicerón ha presentado una concepción finalista de la naturaleza en la que ha apelado ciertamente a la tesis estoica del lógos spermatikós de tradición estoica ${ }^{32}$. Mas en una revisión crítica que -como he expuesto en otros estudios- ha permitido a Cicerón elaborar una cosmología teológica que, en razón de sus filiaciones platónicas, afirma la emergencia de la racionalidad respecto de lo corpóreo $^{33}$. Por ello, como ha observado G. De Plinval, el alcance de la influencia platónica preserva a Cicerón de exponer en De legibus una postura corporalista de la naturaleza como cabría a una actitud meramente receptiva, sin matices, de las enseñanzas estoicas ${ }^{34}$. De allí que

${ }^{29}$ Cfr. en este mismo estudio ap. III.

${ }^{30}$ Domingo de Soto, op. cit., I, q. 1, a.1: "illa vero quam praeposuerat libro I. Lex est ratio summa insita in natura, quae iubet ea quae facienda sunt, prohibetque contraria".

31 Ibid., I, q. 1, a.1: "extra leges naturales non extenditur".

32 Tesis que fuera expresada en las enseñanzas de la Stoa acerca del lógos spermatikós, cfr. Diógenes Laercio, Vitae VII, 136. Scattola. M., se detiene en el influjo estoico en la tradición ciceroniana acerca de la naturaleza de la ley en: "Die 'lex caelestis' des Cicero", Das Naturrecht vor dem Naturrecht. Zur Geschichte des 'ius naturae'.Tübingen, Max Niemeyer Verlag, 1999, pp.25 y ss.

33 Cfr. entre estudios ya citados: Corso de Estrada, L., "Lectura filosófica de la naturaleza", Marco Tulio Cicerón, Sobre las Leyes. Edición Bilingüe, Traducción anotada, Introducción y Apéndices, pp. LXI-LXVII.

34 De Plinval, G., “Introduction”, Cicéron. Traité des Lois, De legibus, op. cit., p. 25. 
a través de la definición de ley natural que ahora nos ocupa, Cicerón expone en De legibus un renovado finalismo de la naturaleza ${ }^{35}$. Postura que ha sostenido de modo continuado en De República ${ }^{36}$ y loci paralelos del De officiis ${ }^{37}$ entre otros pasajes.

\section{III. "Lex aeterna" - racionalidad}

Con motivo de SU Consideración del STATUS QuAestionis acerca de la naturaleza de la ley eterna, Domingo de Soto examina algunas dificultades que proceden de su condición de eternidad. Así: si hubiese una ley eterna no podría promulgarse porque ningún hombre es eterno ${ }^{38}$, o también si hubiese una ley eterna no podría ordenarse a un fin, dado que lo eterno no puede ser referido a otra $\operatorname{cosa}^{39}$; todo lo cual se opondría a los componentes que convienen a la naturaleza de la ley, según son expresados por Tomás de Aquino en Summa Theologiae I-II q. 90, a.4, c. En relación con estas razones, Soto se pronuncia apelando, por una parte, a la autoridad de Agustín, para sostener con él que "la ley eterna es la Razón Suma que existe en Dios" ${ }^{40}$. En este sentido, lo ocupa la argumentación del De libero arbitrio, donde Agustín centra la vía probatoria en la necesidad de que la vida humana, que se desenvuelve en el ámbito de las cosas mutables y temporales, sea regulada por una ordenación que no posea la misma naturaleza, sino una inmutable y eterna. Por lo que en el texto agustiniano se sostiene que la ley temporal no es justa o legítima, a no ser que se encuentre fundada en la "lex aeterna", "que se halla impresa en nosotros" ("quae impressa nobis") ${ }^{41}$. Lo cual supone la connaturalidad de la naturaleza racional humana con respecto a la racionalidad con la que gobierna la ley eterna divina. A partir de lo cual Soto concluye que: "La ley que se denomina Razón Suma, no puede dejar de ser percibida por quien está dotado de inteligencia sino como inconmensurable y eterna", y que "lo eterno que es inmutable sólo existe en Dios" ${ }^{42}$.

\footnotetext{
35 Cfr. M. Crowe, The Changing Profile of the Natural Law, The Hague, M. Nijhoff, 1977, p. XIII.

${ }^{36}$ Cfr. Cicerón, De legibus I, 5, 18: "lex est ratio summa, insita in natura, quae iubet ea quae facienda sunt, prohibetque contraria”.

37 Cfr. Cicerón, De officiis, III, 17, 61.

${ }^{38}$ Cfr. Domingo de Soto, op. cit., I, q. 3, a.2, obj. 1.

39 Cfr. Ibid., I, q. 3, a.2, obj. 2.

${ }^{40}$ Ibid., I, q. 3, a.2: "quam August. [...] afirmat. Scilicet aeternam legem ese rationem summam in Deo existentem".

41 Cfr. Agustín, De libero arbitrio I, 6.

${ }^{42}$ Cfr. Domingo de Soto, op. cit., I, q. 3, a.2, sc: "lex quae summa ratio nominatur, non potest cuipiam intelligenti non incommutabilis aeternaque [...] aeternum autem est incommutabile in solo Deo existit".
} 
Por otra parte, Soto apela a la determinación magistral de Tomás de Aquino en Summa Theologiae I-II, q. 93, a.1, c., cuyo texto repasa con detenimiento para hacer manifiesta su convergencia con la postura agustiniana y para discernir con él que: "dado que la ley (como antes fue dicho) no es otra cosa que el dictamen de la razón práctica por el que el Príncipe gobierna a todos sus súbditos, resulta que la ley eterna no es otra cosa que la sempiterna Razón de su Sabiduría, por la que rige el universo. En efecto, como su substancia y naturaleza [es eterna], resulta que cualquiera de los atributos que existen en Él mismo son eternos" ${ }^{43}$. Pues, en efecto, el escolástico allí subraya el carácter ejemplar de la Razón divina como Sabiduría creadora y, por ende, como artífice del mundo. Pero asimismo, que la Razón divina misma tiene naturaleza de "Lex", dado que "la Razón divina es Sabiduría que mueve a las cosas a su fin debido" ${ }^{4}$.

Soto añade asimismo que las sentencias de Agustín y de Tomás de Aquino desarrollan lo que se enseña en Proverbios 8, 23: "Desde la eternidad fue dispuesta [la Sabiduría], y desde el antiguo tiempo antes de que fuera hecha la tierra" ${ }^{45}$. Pero cabe subrayar que incorpora a las vías probatorias de las auctoritates citadas, la convergencia de Cicerón en De legibus con respecto a la postura expresada por éstas. Por una parte, Soto mismo justifica la significación de este aporte que hace presente como una expresión de la concordancia de los "filósofos" ("philosophi") con las sentencias de las autoridades. Así dice expresamente en relación con la patencia de la ley eterna que: "esta conclusión fue siempre de tanta claridad, que resplandeció incluso ante la [razón] natural, como también los filósofos lo descubrieron" ${ }^{4}$. Y como manifestación de tal hallazgo filosófico y, consecuentemente, de una vía proporcionada al develamiento que la razón natural alcanza de la ley eterna, Soto retorna a De legibus II, en un preciso pasaje de II, 6, 18. Allí, Cicerón ciertamente ofrece sustento a sus palabras, afirmando que los hombres que alcanzaron la sabiduría, alcanzaron por consiguiente la comprensión de la existencia de una ley anterior y superior a la humana y, por ende, eterna, que causa el orden del mundo en su conjunto y que rige a los seres que lo habitan. El pasaje ciceroniano dice, como cita

\footnotetext{
43 Ibid., I, q. 3, a.2: "Igitur cum lex (ut supra dictum est) aliud sit quam dictamen rationis practicae in Principe qua cuncta sibi súbdita gubernat, fit ut lex aeterna in Deo nihil aliud fit quam sempiterna ratio suae sapientiae, qua mundi universitatem regit. Etenim ut sua substantia et natura, fit et quicquid atributuorum in ipso existit aeternum est".

${ }^{4}$ Tomás de Aquino, op. cit., I-II q. 93, a. 1, c.: "ratio divinae sapientiae moventis omnia ad debitum finem, obtinet rationem legis".

45 Domingo de Soto, op. cit., I, q. 3, a.2: "ut ipsa de se sapientia Proverb. 8, praedicat. Ab aeterno ordinata sum, et ex antiquis antequam terra fieret".

${ }^{46}$ Ibid., I, q. 3, a.2: "adeo haec fuit semper conclusio lumine etiam naturali resplandens ut ipsis etiam Philosophis innotuerit".
} 
Soto en De Iustitia et Iure: "Veo, entonces, que fue una sentencia común entre los más sabios que la ley no es creación del ingenio de los hombres, ni una resolución de los pueblos, sino algo eterno, que rige el mundo entero por la sabiduría de lo que ordena y de lo que prohíbe. De tal manera que [esos sabios] decían que aquella primera y suprema ley es el Entendimiento del Dios que conforme a la razón establece ya las obligaciones, ya las prohibiciones para todas las cosas. De allí que aquella ley que los dioses concedieron al género humano es alabada con justicia" ${ }^{47}$.

Como exégeta de este texto, Soto advierte en él una tesis central de la tradición ciceroniana. Sin duda, la afirmación de la realidad de una Ley Primera Rectora que se predica de lo divino; más allá de la complejidad del texto ciceroniano en relación con la naturaleza propia de lo divino, en lo cual Soto no parece detenerse tal vez debido al valor propedéutico que asigna a su fuente. Pero el maestro salmantino subraya asimismo -en el texto que nos ocupa- la identificación ciceroniana de la Ley eterna con el Entendimiento divino del cual dimana, como causa del orden perfectivo del mundo en su conjunto. Tesis que ciertamente Soto somete a su propia lectura, al resignificar la índole del Entendimiento divino que la misma porta como una anticipación de la concepción de la Razón divina misma que, como Principio causal, se manifiesta en el orden perfectivo de la totalidad del mundo, como efecto de su obra creadora. Soto parece apreciar la convergencia de este testimonio más allá de sus limitaciones propias, probablemente porque revela la capacidad que en él se concede a la razón natural del hombre para ascender hasta la racionalidad divina ${ }^{48}$. De hecho, numerosos pasajes de Cicerón en De legibus y en otras obras suyas, también podrían apoyar la pertinencia de la exégesis de Soto. Sólo a modo de mención, y para seguir en la línea de las citas de Soto, me detengo en otro locus de De legibus en el que precisamente se describe tal proceso de develamiento que el hombre puede hacer de lo divino: "Cuando haya examinado el cielo, la tierra, los mares y la naturaleza de todas las cosas, y comprenda cuál es el Principio del que éstas han sido generadas y a dónde deben retornar. Cuando [conozca] [...] qué hay en ellas de mortal y de perecedero, qué de divino y eterno, y cuando de algún modo se haya asido al mismo Dios que dispone y gobierna [...] a través de esta contem-

\footnotetext{
${ }^{47}$ Cicerón, De legibus II, 4, 8: "Hanc igitur video sapientissimorum fuisse sententiam, legem neque hominum ingeniis excogitam, nec scitum aliquod ese populorum. Sed aeternum quiddam, quod universum mundum regeret imperandi prohibendique sapientia. Ita principem legem illam et ultimammentem ese dicebant omnia ratione aut cogentis aut vetantis dei. Ex qua illa lex quam di humano generi dederunt, recte est laudata". Hasta aquí, el texto latino de De legibus II, 4, 8 que cita debidamente Domingo de Soto en op. cit., I, q. 3, a.2, c.

48 Ramos Lisson, D., se detiene también en la convergencia que indico supra, en relación con la aportación ciceroniana y, con ella, la búsqueda de una fundamentación de razón natural; cfr. "Ley eterna y Ley Evangélica. Sus relaciones según Domingo de Soto", Scripta Theologica, Facultad de Teología de la Universidad de Navarra, 5/1, 1973, p. 95 .
} 
plación y de este conocimiento de la naturaleza, ¡oh dioses inmortales, cómo será el conocimiento que alcance de sí mismo!” 49 .

Conforme a estos testimonios que conciernen a un plano epistemológico de rango propiamente filosófico a favor de la existencia de la ley eterna, Soto sostiene que: "se sigue que la ley eterna no se identifica con la ley divina", como en los casos de la ley Mosaica y de la Evangélica ${ }^{50}$. Bajo este respecto, ratifica en ad 1: "No existe ningún mortal ante quien no resplandezca en algo el conocimiento de la verdad, y toda verdad es -como dice Agustín en De Vera Relig.- cierta irradiación y participación de la ley eterna" ${ }^{51}$. Y la ley eterna es, como también precisa en ad 2: la que no se ordena a un fin, sino que por ella misma Dios ordena las cosas en relación con Él mismo, porque "es Alfa y Omega, Principio y Fin" 52 .

En De legibus, Cicerón ha dado asimismo amplio sustento para que Soto apoye en su testimonio la connaturalidad de la racionalidad humana con respecto a la divina, lo cual justifica que la racionalidad humana posea la aptitud para acceder a la contemplación de lo supra-humano. Así, el locus en el que Cicerón declara que el hombre "fue generado por el supremo Dios con una condición superior", dado que "entre todas las clases de animales y entre los seres de la naturaleza, sólo él participa de la razón y del pensamiento" ${ }^{53}$. Por lo que Soto también puede concordar con él, en cuanto a la aptitud de la racionalidad humana para develar "aquella primerísima [ley eterna] y principio de todas las cosas que se manifiesta en la naturaleza" ${ }^{54} \mathrm{y}$, consecuentemente, acoger la tradición ciceroniana de la ley natural, participada de modo específico en la racionalidad humana. En ese contexto teórico Soto define que "Dios imprimió en nosotros su ley eterna, como un cierto signo de Él mismo en nosotros" 55 . Por lo que resulta definida la jerarquía metafísica de la ley eterna, y

${ }_{49}$ Cicerón, De legibus I, 23, 61: "quom caelum, terras, maria rerumque omnium naturam perspexerit, eaque unde generata quo recursura, quando [...] quid in iis mortale et caducum, quid divinum aeternumque sit viderit, ipsumque ea moderantem et regentemtem deum paene prenderit [...] in hoc conspectu et cognitione naturae, dii inmortales, qualem, se ipse noscet! Cfr. en el contexto de esta misma postura ciceroniana: De republica VI, 13,$13 ; 17,17 ; 20,20$, passim.

${ }^{50}$ Domingo de Soto, op. cit., I, q.3, a.2: "Ex hac conclusione fit consequens no converti legem aeternam ac divinam".

51 Ibid., I, q.3, a.2: "Nulli enim mortalium esistunt quibus non cognitio quaepiam veritatis effulgeat: veritas autem omnis (ut lib. vera relig. autor est August.) irradiatio quaedam est et participatio legis aeternae".

52 Ibid., De Iustitia et Iure I, q.3, a.2: "qui est A et $\Omega$ Principium et finis".

53 Cicerón, De legibus I, 7, 22: "hoc [...] quem vocamus hominem, praeclara quadam conditione generatum esse a supremo deo. Solum est enim ex tot animantium generibus atque naturis particeps rationis et cogitationis".

${ }^{54}$ Domingo de Soto, op. cit., I, q.3, a.2: "Unde Cicero lib.2 [...] ad illam antiquissimam et rerum omnium principem expressa naturam"

55 Ibid., I, q. 5, a.2: “Deus aeterna suam legem nobis impressit quae esset sicut certum illius signum”. En este sentido, tiene interés la consideración de Massini Correas acerca del fundamento de la normatividad de la naturaleza, ciertamente ya presente en la elaboración de Tomás de Aquino, dado que la normatividad no tiene sustento 
su participación en la ley natural impresa en la racionalidad humana. Lo cual, como sostuvo Cicerón en De legibus I, a continuación de la definición de ley natural que evoca Soto en la Q. 1 (que ya hemos vertido supra): "cuando se afianza y perfecciona en la mente humana es ley" ${ }^{56}$. Lo que define de modo semejante en De legibus II, al afirmar que tal ley "es razón y entendimiento del sabio, apta para ordenar y para prohibir" ${ }^{57}$.

La consideración de la naturaleza de la ley eterna ya había movido a Soto algo antes a reconocer la aportación del "divus Plato" 58 en el mismo sentido, porque coincide con él en la ordenación de lo humano a lo divino y, consecuentemente, en que "la fuente y el origen de todas las leyes es la ley eterna que es el Entendimiento divino" ${ }^{59}$. De allí que asentada la jerarquía metafísica de la ley eterna, apoyado en la autoridad de Tomás de Aquino y en antecedentes agustinianos, pero con la aportación de la elaboración filosófica del De legibus ciceroniano en torno al binomio ley eterna-racionalidad, Soto ha fundado en la impresión de la ley eterna en la racionalidad humana la razón de ser de la dependencia de la "lex humana" de la universalidad matriz de la ley natural ${ }^{60}$. Asimismo, y en la medida en que ha concedido significación al esfuerzo especulativo del De legibus ciceroniano por concebir la naturaleza de la ley eterna, ha legado una relectura acerca de la causalidad del finalismo de la naturaleza, de la connaturalidad de la razón natural con respecto a la ley eterna, y del orden causal del mundo, en el contexto de una participación transversal de la racionalidad -desde el plano de la racionalidad divina al de la racionalidad natural del hombre-. Finalmente, y con fina exégesis, ha hecho explícita la convergencia del Tractatus De legibus de Summa Theologiae con tesis de tradición ciceroniana a las que Tomás de Aquino no ha sido ajeno ${ }^{61}$.

en la naturaleza misma sino en la razón divina misma. Lo cual enfatiza Soto en el pasaje, como he procurado subrayar, incorporando expresamente la aportación ciceroniana para la elaboración de dicha tesis; cfr. Massini Correas, C., La ley natural y su interpretación contemporánea, Pamplona, EUNSA, 2006, p. 64.

${ }^{56}$ Cicerón, De legibus I, 6, 18: “cum est in hominis mente confirmata et perfecta, lex est".

57 Ibid., II, 4, 8: "est enim ratio mensque sapientis ad iubendum et ad deterrendum idónea”.

58 Domingo de Soto, op. cit., I, q. 1, a.2.

59 Ibid., I, q. 1, a.2: "Fons et origo legum ómnium aeterna lex est divina mentis".

${ }^{60}$ Ibid., I, q. 5, a.2.

${ }^{61}$ En esta línea de recepción de la tradición ciceroniana, entre otros trabajos citados: Corso de Estrada, L., "Proyecciones de la tradición ciceroniana sobre la ley natural. Fases medievales y de la modernidad temprana", Marco Tulio Cicerón, Sobre las Leyes. Edición Bilingüe, Traducción anotada, Introducción y Apéndices, op. cit., pp. 261-287. 


\section{REFERENCIAS BiBLIOGRÁFICAS}

Barnes, J., "Antiochus", Philosophia Togata I, Griffin, M. , Barnes, J. (edd.), Oxford, Clarendon Press, 1997, pp. 51-96.

De Plinval, G., "Introduction", Cicéron. Traité des Lois, De legibus, Téxte établi et traduit, Paris, Les Belles Lettres, 1968, pp. VI-LXVI.

Corso de Estrada, L., Marco Tulio Cicerón, Sobre las Leyes. Edición Bilingüe, Traducción anotada, Introducción y Apéndices, Buenos Aires, COLIHUE-CLÁSICA, 2019.

Corso de Estrada, L., "Natura ut ratio. Componentes del finalismo de tradición estoica en Rabano Mauro, Felipe Canciller y Tomás de Aquino", De natura, La naturaleza en la Edad Media, J. Fuertes Herreros-A. Poncela González (edd.), Salamanca, Ediciones Húmus, Gabinete de Filosofía Medieval-Publicaciones Salamanca, 2015, vol. I, pp. 63-79.

Corso de Estrada, L., "Tesis helenísticas en exégesis escolásticas: 'Conformidad con la naturaleza': Alberto Magno, Tomás de Aquino y Domingo de Soto", Right and Nature in the First and Second Scholasticism, Rencontres de Philosophie Médiévale, A. Culleton-R. Hofmeister Pich (edd), Turnhout, Brepols, 2014, pp. 271-284.

Corso de Estrada, L., Naturaleza y vida moral. Marco Tulio Cicerón y Tomás de Aquino, Pamplona, EUNSA, 2008.

Crowe, M., The Changing Profile of the Natural Law, The Hague, M. Nijhoff, 1977.

Lévy, C., Cicero Academicus. Recherches sur les Académiques et sur la Philosophie Cicéronienne, Paris-Rome, Palais Farnèse-École Française de Rome, 1992.

Massini Correas, C., La ley natural y su interpretación contemporánea, Pamplona, EUNSA, 2006.

Ramos Lisson, D., "Ley eterna y Ley Evangélica. Sus relaciones según Domingo de Soto", Scripta Theologica, Facultad de Teología de la Universidad de Navarra, 5/1, 1973, pp. 91-126.

Scattola, M., "La virtud de la justicia en la doctrina de Domingo de Soto", Anuario Filosófico 45/2, 2012, pp. 313-341.

Scattola, M., Das Naturrecht vor dem Naturrecht. Zur Geschichte des 'ius naturae'. Tübingen, Max Niemeyer Verlag, 1999. 
Turpin, J., "Cicéron, De legibus I-II et la religion romaine: une interpretation philosophique à la veille du principat", Aufstieg und Niedergang der Römischen Welt, 1986, II/ 3, pp. 1877-1908.

DOI: https://doi.org/10.15366/bp2021.26.003

Bajo Palabra. II Época. No26. Pgs: 59-74 